\title{
Comprehensive drilling of the C1-2 facets to achieve direct posterior reduction in irreducible atlantoaxial dislocation
}

\author{
Pravin Salunke, MCh, ${ }^{1}$ Sushanta K. Sahoo, MS, ${ }^{1}$ Arsikere N. Deepak, MS, ${ }^{1}$ \\ Mandeep S. Ghuman, MD, ${ }^{2}$ and Niranjan K. Khandelwal, MD² \\ Departments of ${ }^{1}$ Neurosurgery and ${ }^{2}$ Radiodiagnosis, Postgraduate Institute of Medical Education and Research, Chandigarh, \\ India
}

\begin{abstract}
OBJECT The cause of irreducibility in irreducible atlantoaxial dislocation (AAD) appears to be the orientation of the C1-2 facets. The current management strategies for irreducible AAD are directed at removing the cause of irreducibility followed by fusion, rather than transoral decompression and posterior fusion. The technique described in this paper addresses C1-2 facet mobilization by facetectomies to aid intraoperative manipulation.

METHODS Using this technique, reduction was achieved in 19 patients with congenital irreducible AAD treated between January 2011 and December 2013. The C1-2 joints were studied preoperatively, and particular attention was paid to the facet orientation. Intraoperatively, oblique $\mathrm{C} 1-2$ joints were opened widely, and extensive drilling of the facets was performed to make them close to flat and parallel to each other, converting an irreducible AAD to a reducible one. Anomalous vertebral arteries (VAs) were addressed appropriately. Further reduction was then achieved after vertical distraction and joint manipulation.
\end{abstract}

RESULTS Adequate facet drilling was achieved in all but 2 patients, due to VA injury in 1 patient and an acute sagittal angle operated on 2 years previously in the other patient. Complete reduction could be achieved in 17 patients and partial in the remaining 2. All patients showed clinical improvement. Two patients showed partial redislocation due to graft subsidence. The fusion rates were excellent.

CONCLUSIONS Comprehensive drilling of the C1-2 facets appears to be a logical and effective technique for achieving direct posterior reduction in irreducible AAD. The extensive drilling makes large surfaces raw, increasing fusion rates.

http://thejns.org/doi/abs/10.3171/2014.12.SPINE14310

KEY WORDS irreducible atlantoaxial dislocation; facetectomy; reduction; realignment; technique; facets; C1-2 joints

$\mathrm{T}$ HE management of atlantoaxial dislocation (AAD) is challenging due to the neural structures the craniovertebral junction (CVJ) houses and the proximity of the vertebral arteries (VAs). The dislocation may be reducible or irreducible. The reducible AAD can be defined as C1-2 alignment on extension or application of cervical traction. If the dislocation cannot be reduced despite cervical traction, it is labeled as an irreducible AAD. Management becomes difficult with irreducibility of the dislocation. Currently, the focus in treating such patients has shifted to the dislocated $\mathrm{C} 1-2$ facets rather than the dens.
Since Goel's description of C1-2 distraction, intraoperative joint manipulation has been the preferred method of treatment for irreducible AAD. ${ }^{1,2}$ In the recent past, various techniques of joint manipulation have been described to achieve reduction. ${ }^{6,8}$ However, little has been described about C1-2 facet mobilization using facet osteotomies. We have focused on treating the cause of irreducibility and joint mobilization by facet osteotomy apart from joint manipulation, and described the technique thereof.

The cause of irreducibility is likely to be the orientation of the C1-2 facets. ${ }^{5}$ In congenital irreducible AAD,

ABBREVIATIONS AAD = atlantoaxial dislocation; $A D I=$ atlantodental interval; CVJ = craniovertebral junction; JOA = Japanese Orthopaedic Association; VA = vertebral

artery.

SUBMITTED June 26, 2014. ACCEPTED December 30, 2014.

INCLUDE WHEN CITING Published online May 29, 2015; DOI: 10.3171/2014.12.SPINE14310.

DISCLOSURE The authors report no conflict of interest concerning the materials or methods used in this study or the findings specified in this paper. 
the $\mathrm{C} 1-2$ joints are deformed. The angulation of the facets gives rise to progressive slippage of $\mathrm{C}-1$ over $\mathrm{C}-2$, until at some point it becomes irreducible (Fig. 1A-F). ${ }^{5}$ Facetectomy is likely to address the cause of irreducibility and help in mobilizing the dislocated/deformed joint (Fig. 1G and $\mathrm{H}$ ). In this paper we describe a technique of comprehensive drilling of the $\mathrm{C} 1-2$ facets (facetectomy) to eliminate the cause of irreducibility, and report our experiences with this technique.

\section{Methods}

\section{Patient Population}

Nineteen patients with congenital irreducible AAD were admitted to the Postgraduate Institute of Medical Education and Research, in Chandigarh, India, between January 2011 and December 2013. Irreducibility was de- fined as nonalignment of $\mathrm{C} 1-2$ (determined on lateral CVJ radiography) after extension (neck movement) or application of cervical traction (for 48 hours). Crutchfield cervical traction was applied, starting with 7\%-8\% of body weight (2-5 kg depending on age and weight). The head of the bed was elevated to provide counter traction. The weight was increased every 4 hours by 0.5 to $1 \mathrm{~kg}$, to a maximum of $12 \%-13 \%$ of body weight. Serial radiographs were assessed for reduction. Those patients who demonstrated a reduction were excluded from the study. The patients who underwent operations in the 1st year were studied retrospectively and the remaining patients were evaluated prospectively. Proper informed consent was obtained from all patients.

\section{Clinical Features}

Patients presented with pyramidal tract involvement (n

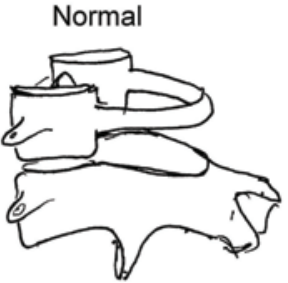

A

\section{C1-2 Facets in IrCAAD}

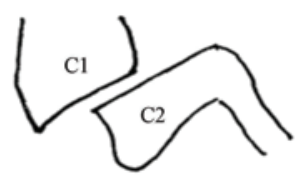

D

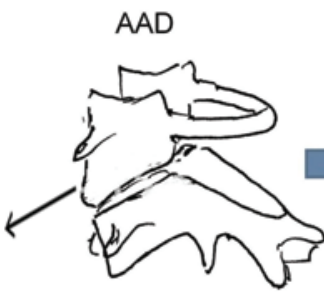

$\mathbf{B}$

\section{On Flexion}

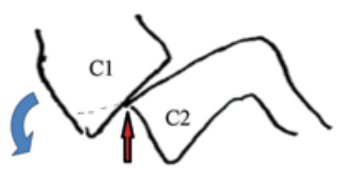

$\mathbf{E}$
Progression of AAD to irreducibilty

Portion of facets to be drilled to make the joints relatively flat and aid reduction

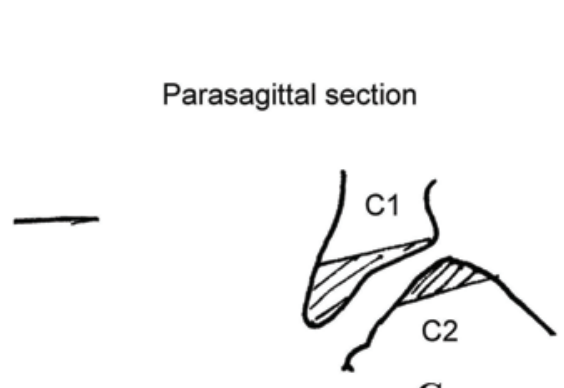

G

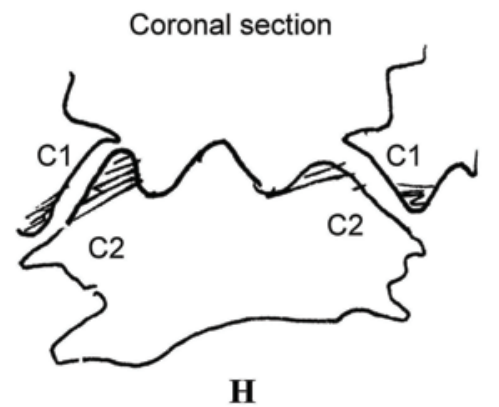

FIG. 1. Sketches of the C1-2 joint. A: A normal C1-2 joint viewed from a posterolateral aspect. B: Position of the C1-2 joint in cases of AAD. Note the obliquity of the C1-2 facets as compared with normal. The thin arrow shows the direction of progressive dislocation due to obliquity of the facets. C: Dynamic progression of AAD (thick arrow from B to C). D-F: Parasagittal section of the $\mathrm{C} 1-2$ facets in cases of congenital irreversible AAD. Due to the obliquity, the dislocation does not reduce on extension. The posterosuperior edge of $\mathrm{C}-2$ acts as a ledge preventing reduction (red arrow in $\mathrm{E}$ ). C-2 cannot be pushed anterior to $\mathrm{C}-1$ due to the anteroinferior edge of $\mathrm{C}-1$ (red arrow in F). Blue arrows represent the forces during flexion and extension that act on the $\mathrm{C} 1-2$ facets. G and H: The shaded areas show the portion of the C1-2 facets (congenital irreducible AAD) to be drilled to make the joint relatively flat, helping to achieve reduction, with respect to the hard palate represented by the line to the left of panel G. The correction of vertical dislocation would require a spacer/bone strut graft. Figure is available in color online only. 
$=18)$, posterior column involvement $(\mathrm{n}=12)$, spinothalamic tract involvement, respiratory distress and bladder involvement $(n=6)$, and torticollis $(n=9)$. All patients had some stigmata (such as high-arched palate, low hairline, or short neck) suggesting a congenital deformity of the upper cervical spine.

The Japanese Orthopaedic Association (JOA) scale score was used to quantify the disabilities. Based on the JOA scale score, patients were classified into 1 of 3 groups. Those patients with scores $\leq 10$ were classified as fully dependent $(n=11)$, those with scores $11-14$ as partially dependent, and 15-17 as independent.

\section{Radiological Details}

Flexion-extension radiographs confirmed the irreducibility of the AAD, and the atlantodental interval (ADI) was calculated using these radiographs. In addition, bone abnormalities such as occipitalized arch of the atlas, bifid arch, os-odontoideum, and C2-3 fusion were investigated. MR images and CT scans of the CVJ were obtained in all patients. MR images were studied to determine cervicomedullary compression, T2 signal change, associated Chiari malformation, and syringomyelia. CT scans confirmed the AAD and bone abnormalities. Axial images were studied at the level of C-1 to look for the body of C-2, suggesting central (vertical) dislocation or telescoping. CT scans of the CVJ were reconstructed in the sagittal and coronal planes. The inferior sagittal C-1 facet angles were calculated in the parasagittal sections. ${ }^{5}$ Additionally, a CT angiogram was obtained in the last 14 patients enrolled in the study to investigate an anomalous VA or its branches. Skeletal traction was applied 48 hours prior to surgery in all patients. None of the patients showed reduction following traction.

\section{Surgical Technique}

The patients underwent the operations while prone. The C-2 lamina was traced to the C-2 facet. Bilateral C-2 root ganglia were transected to obtain a panoramic view of the C1-2 joints. The anomalous VA was addressed appropriately, by dissecting and safeguarding it. ${ }^{3,4}$ Preoperative CT angiography defined the course of anomalous VAs. The dissection began on the normal side, or the side with a less dominant artery in cases of bilateral anomalous arteries. ${ }^{3,4}$ As a rule, the $\mathrm{C}-2$ root ganglion was observed dorsal to the anomalous artery. The ganglion was dissected and cut. The soft tissue was teased out to dissect the artery. The artery was then dissected along its course. ${ }^{3,4}$ The dissected loop of the artery was usually redundant and after dissection could be gently retracted superiorly or inferiorly to safeguard it while drilling the facets and inserting C-1 lateral mass screws. ${ }^{3,4}$ The artery was protected while inserting the C-2 pedicle screw, especially with a medial loop. The medial portion of the transverse foramen was defined, and a thin dissector was placed there that acted as a barrier between the artery and the drill/screw. Finally, care was taken not to compromise the anomalous artery while fastening the screws by leaving adequate space between the rod and artery. ${ }^{4}$

In congenital $\mathrm{AAD}$, the height of the wedge to be drilled from each facet required to make the joint close to flat or reducible was given by the formula:

1/2[sin(180 - inferior sagittal C-1 angle $)-\sin 30] \times$ [anteroposterior length of facet],

although it was not possible to measure it intraoperatively. ${ }^{5}$ An approximation would be to reach up to the anterior edge of the C-1 facet undercutting the surface so that the anterior capsule and soft tissue is visualized easily. In severe subluxation with oblique orientation of the facets, the joint space is not observed while dissecting the C-2 lamina and C-1 posterior arch. The drilling of the posterior-superior wedge of the $\mathrm{C}-2$ facet was performed until the joint space and posterior surface of the C-1 facet could be seen. A thin osteotome was then inserted in the joint space to open the joint. The drilling then was continued more on the $\mathrm{C}-1$ facet surface, especially the anterior portion. Intermittent insertion of an osteotome, or even applying suction and using it as a lever with the posterior edge of the C-2 facet as a fulcrum, improved the visibility of the anterior portion of the $\mathrm{C}-1$ facet that required drilling. The visualization of the anterior joint capsule and soft tissue provides a rough idea of adequate drilling (Figs. $1 \mathrm{G}$ and $\mathrm{H}$ and 2). The entire edge of the facet from the medial to lateral aspect was drilled so that the facet surfaces became flat. Care was taken so that no bone ledge remained that would prevent reduction. The lateral wedge of the C-1 facet and medial wedge of C-2 were drilled to make the joint flat in the coronal plane (Figs. 1 and 2).

With this type of drilling, the C1-2 joint is mobilized completely, converting an irreducible subluxation to a reducible one. Pressing the C-2 spinous process anteriorly should align the C1-2 facets and is a simple maneuver to check for complete facet mobilization. Reduction was then maintained with the use of spacers (bone alone or metallic spacers packed with bone) and C1-2 was fused uisng sublaminar wires or polyaxial screws. The bone graft was harvested from the seventh or eighth rib posteriorly and cut into small pieces and thin slices. The small pieces were packed into the drilled joint, followed by the spacer packed with these grafts. Next, the remaining pieces were again placed posterior to the spacers between the C1-2 joint. The slices were placed between decorticated surfaces of the occiput/C-1 arch and C-2 lamina.

We switched to using polyaxial screws after using sublaminar wire in the first 3 patients. After insertion of spacers the vertical reduction can be achieved completely. In the last 1.5 years, $\mathrm{C} 1-2$ polyaxial screws were inserted, and further anteroposterior and rotational alignment was achieved using modification of a technique described by Suh et al. ${ }^{5} \mathrm{~A}$ long rod holder holds the rod loosely fastened in $\mathrm{C}-1$ and $\mathrm{C}-2$ polyaxial screws. After tightening the rod over the C-2 screw and slightly distracting the $\mathrm{C} 1-2$ screws, the rod holder was used as a lever and the C-2 screw tulip as a fulcrum. The rotation of the handle of the rod holder in various directions corrects anteroposterior, rotational, or lateral components of dislocation. Alignment of the midpoint of the $\mathrm{C}-1$ posterior arch and $\mathrm{C}-2$ spinous process suggested complete reduction. Final tight- 

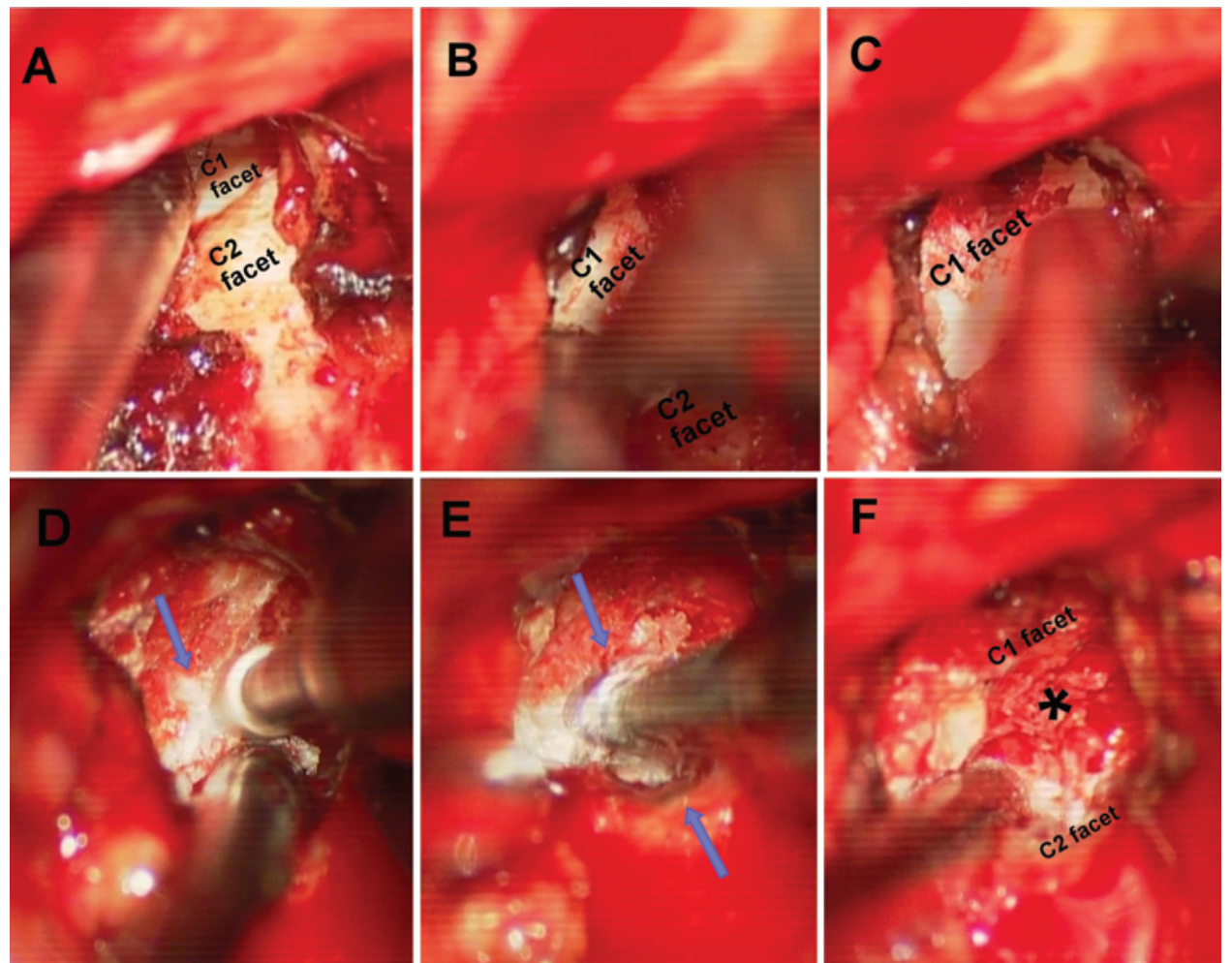

FIG. 2. Intraoperative photographs. A: The left C1-2 joint in a patient with congenital irreversible AAD. The C-2 facet is observed posterior to C-1. B: Opening the C1-2 joint. C: The articular cartilage is removed from the facet surface. D: The anterior inferior wedge of the C-1 facet (arrow) to be drilled. E: The anterior edge of C-1 forming the ledge undergoing drilling (upper arrow). The drilled posterosuperior margin of C-2 has also been drilled (lower arrow). F: Adequate drilling has been achieved. The anterior capsule and soft tissue (asterisk) are visualized without distraction. The capsule needs to be visualized along the entire anterior margin from lateral to medial to confirm that no ledge is remaining. Figure is available in color online only.

ening in the aligned position was performed after slightly compressing the $\mathrm{C} 1-2$ screws.

\section{Follow-Up}

Clinical and radiological evaluation was performed at regular intervals. The JOA scale score was compared with preoperative scores. Lateral radiographs of the CVJ in flexion and extension were obtained after 3 months. The inferior sagittal $\mathrm{C}-1$ facet angle was calculated again using a postoperative $\mathrm{CT}$ scan. Bone fusion between the $\mathrm{Cl}-2$ facets was evaluated by both a radiologist and surgeon using a CT scan obtained 4-6 months after surgery. Thin reconstructed and reformatted (sagittal and coronal) CT scans were obtained to investigate fusion maturation and bone growth, as has been described for lumbar fusion. ${ }^{7}$ With thin CT scans, the scatter effect from newer metallic spacers is not an obstacle to interpretation. ${ }^{7}$ The entire construct was evaluated. Fusion was defined as bone trabeculae between the C1-2 facets or lamina and arch on CT without any gap in between (with no mobility on flexion-extension radiographs). In the presence of metallic spacers, particular attention was paid to the areas that were lateral, anterior, and posterior to the spacers. Cystic lucencies around the implants or along endplates and linear defects within the bridging trabeculae suggested nonfusion and required a repeat CT scan after 6 more months. ${ }^{7}$ An early CT scan at 4-6 months also showed subsidence or construct failure.

\section{Results}

The preoperative and postoperative modified JOA scale score, ADIs, and inferior C-1 sagittal facet angles for all patients are listed in Table 1. All patients improved postoperatively. Fourteen patients became independent (JOA score $\geq 15$ ). Five patients improved from completely dependent to partially dependent (JOA score 11-14). Bone anomalies such as occipitalized arch of the atlas, C2-3 fusion, and central/vertical dislocation were noted in most of the patients with relatively acute inferior sagittal C-1 facet angles. The initial 3 patients in whom the technique was attempted were those who showed partial reduction after traction. Later, as the authors gained confidence, all patients with irreversible AAD underwent operations using this technique (Figs. 3 and 4). Vertebral artery injury (possibly anomalous) was encountered in 1 patient, in whom CT angiography was not obtained. A CT angiogram was obtained in the last 14 patients. Of the 28 VAs studied, 11 demonstrated an unusual and anomalous course, including fenestration in 1, persistent first intersegmental artery in 3, inverted VA (lateral variant of first intersegmental artery) in 3, and medial loop in 4.,4 All of these arteries were dissected and safeguarded during the surgery as described above. There was no injury to any of these arteries. The facets were drilled flat to make the inferior sagittal C-1 facet angle more than $170^{\circ}$, except in 2 patients (1 


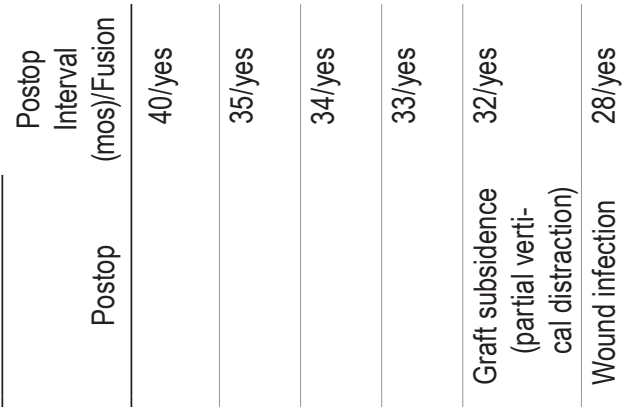

产

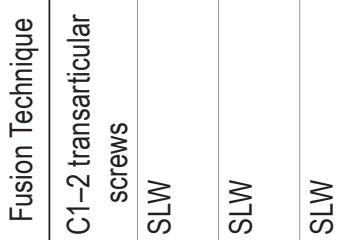

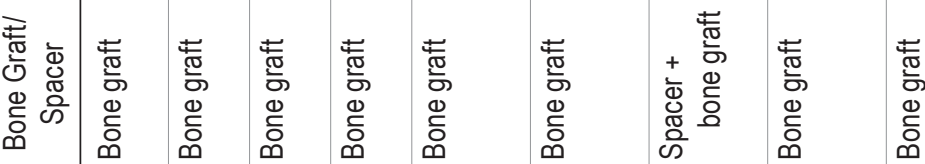

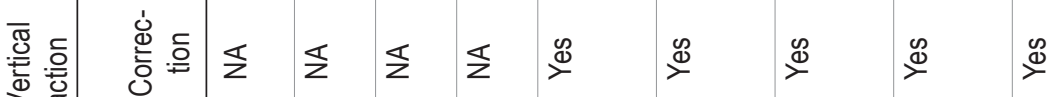

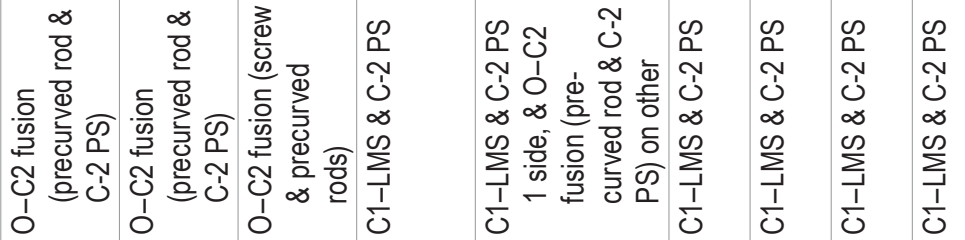

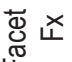

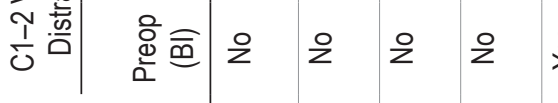
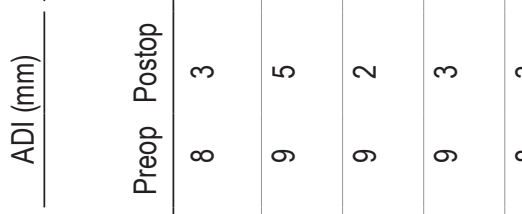

을 $\infty$

\section{ت요 은}

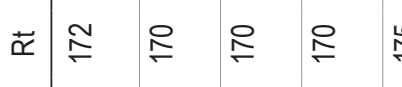

을

\pm 응

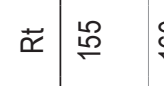

总

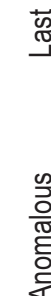

䙳

离

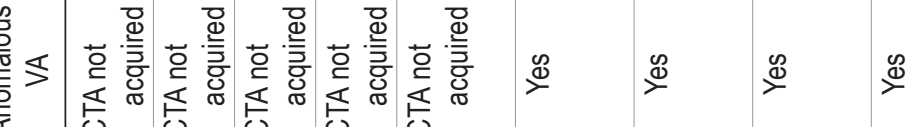

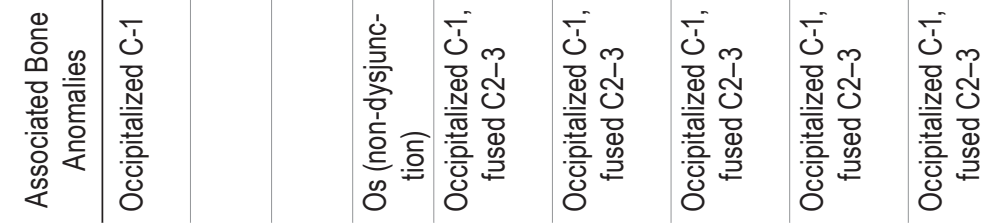

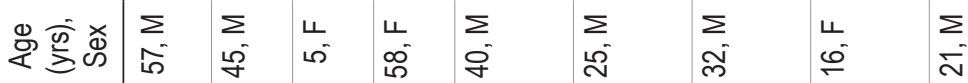

迩 $\dot{z}$ $\frac{1}{} \quad \stackrel{\infty}{\circ} \underset{\infty}{\circ}$

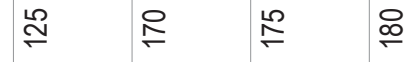

욜 욜

요 유 유

$\because \quad$ F

$\because \quad \therefore \quad=$

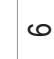

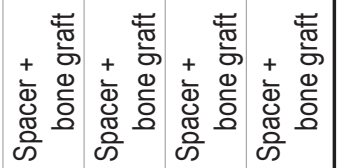

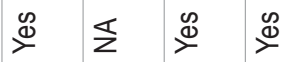

$\mp \stackrel{\infty}{2} \stackrel{\infty}{=}$

$\stackrel{\circ}{\circ} \stackrel{\circ}{\circ} \stackrel{\circ}{\circ}$

$\stackrel{\circ}{\circ} \stackrel{\circ}{\circ}$

으 은

ำ 은

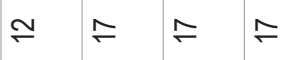

$\sim \circ \div$

운 윤

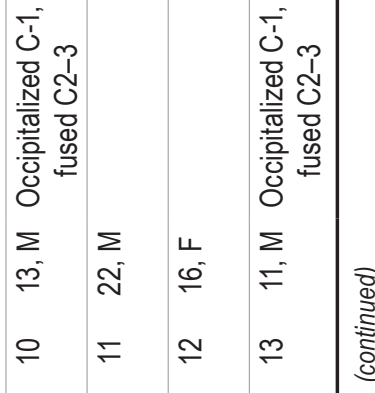




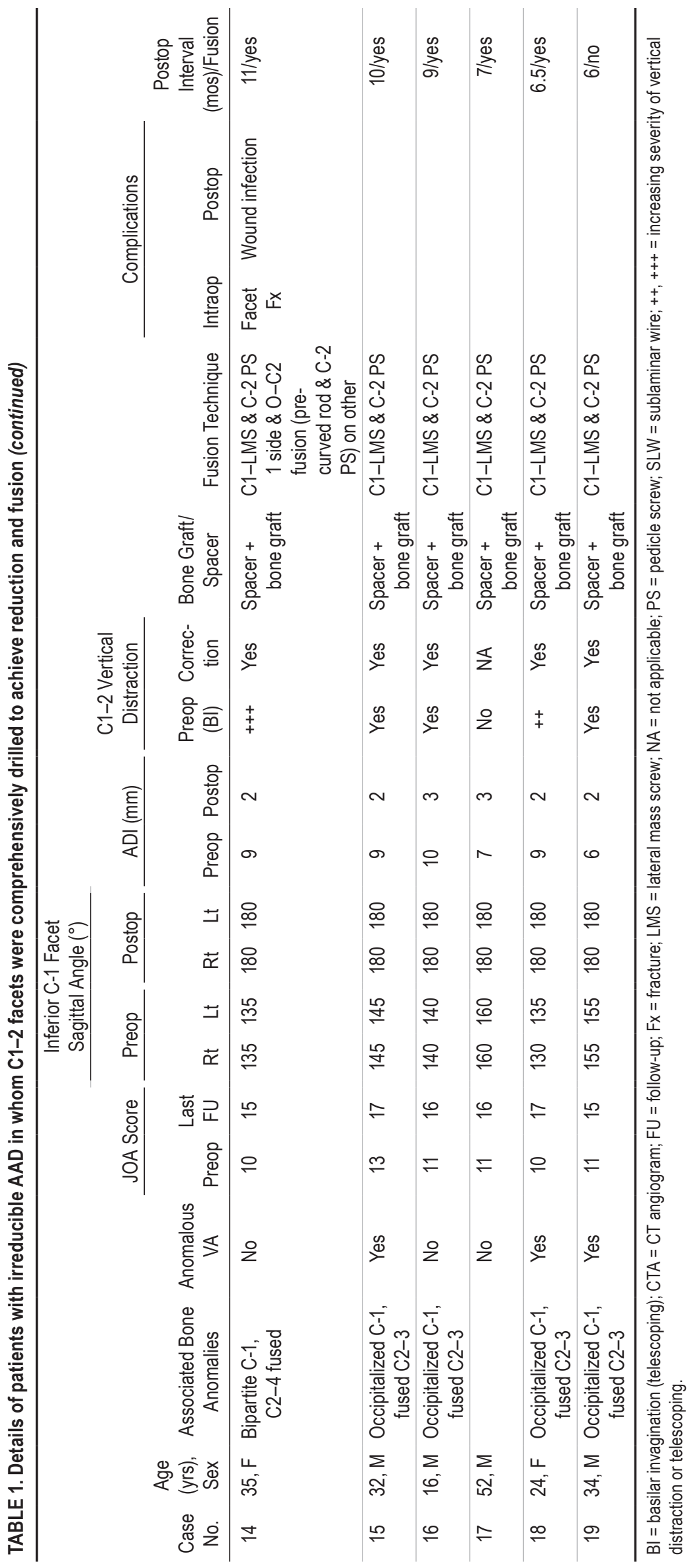



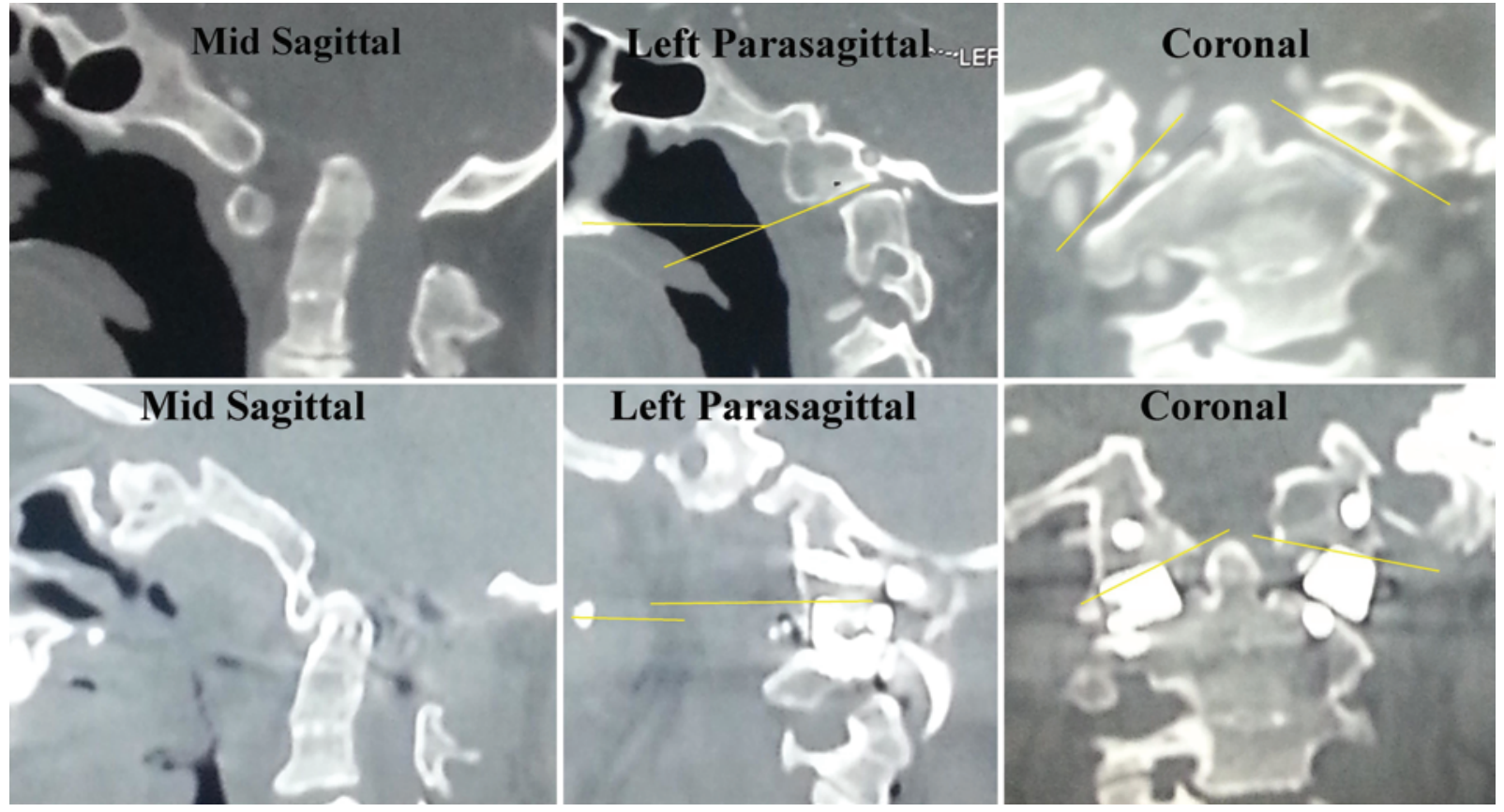

FIG. 3. Upper row: Preoperative CT scans showing vertical and anteroposterior AAD. The parasagittal section through the left C1-2 joints shows the acute C-1 inferior sagittal facet angle (yellow lines). Coronal section shows oblique C1-2 joints (yellow lines). Lower row: Postoperative CT scans showing correction of AAD. Parasagittal CT scan shows drilled-off anterior-inferior C-1 and posterior superior C-2 facet wedges, making the C1-2 joints flat (yellow lines). In the coronal section the medial aspect of the C-2 facet has been drilled to make the joints less vertical (yellow lines). The bone grafts (strut)/spacers correct the vertical dislocation and aid in fusion. Figure is available in color online only.

in whom a VA injury occurred and another with an acute sagittal angle operated on 2 years previously). Satisfactory reduction was achieved in all patients. The alignment was more optimal in the last year and a half of the study (ADI $\leq 2 \mathrm{~mm}$ ).

All patients showed clinical improvement. CT scans obtained before discharge showed good reduction (ADI $\leq$ $3 \mathrm{~mm}$ ) in 17 patients (Fig. 3). In the remaining 2 patients in whom partial reduction was achieved, the cause was incomplete drilling in 1 patient due to VA injury.

The sublaminar wires were used in the initial days when direct reduction was attempted in patients with rela-
A

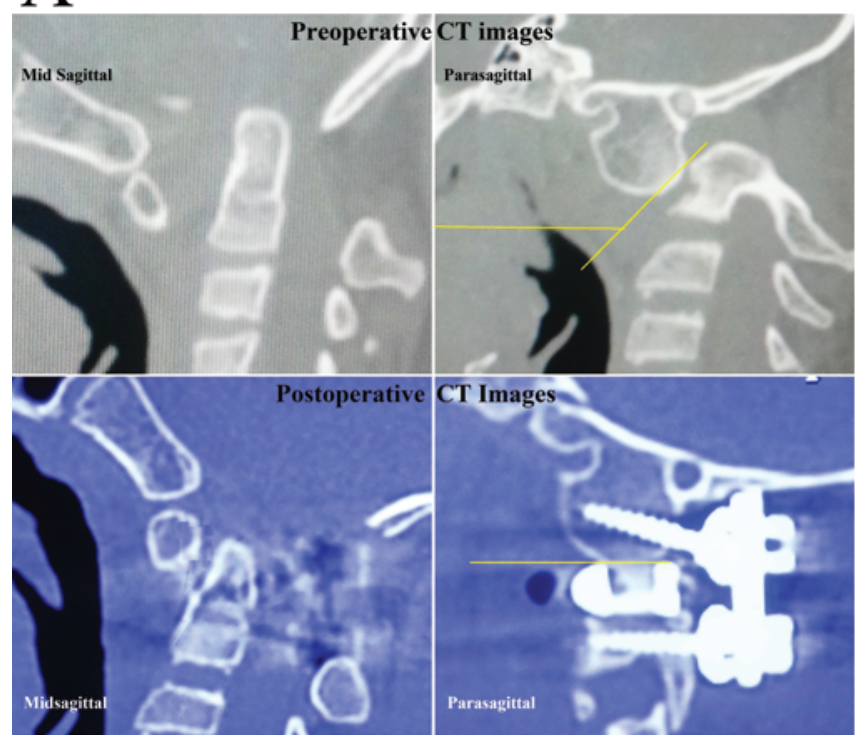

B

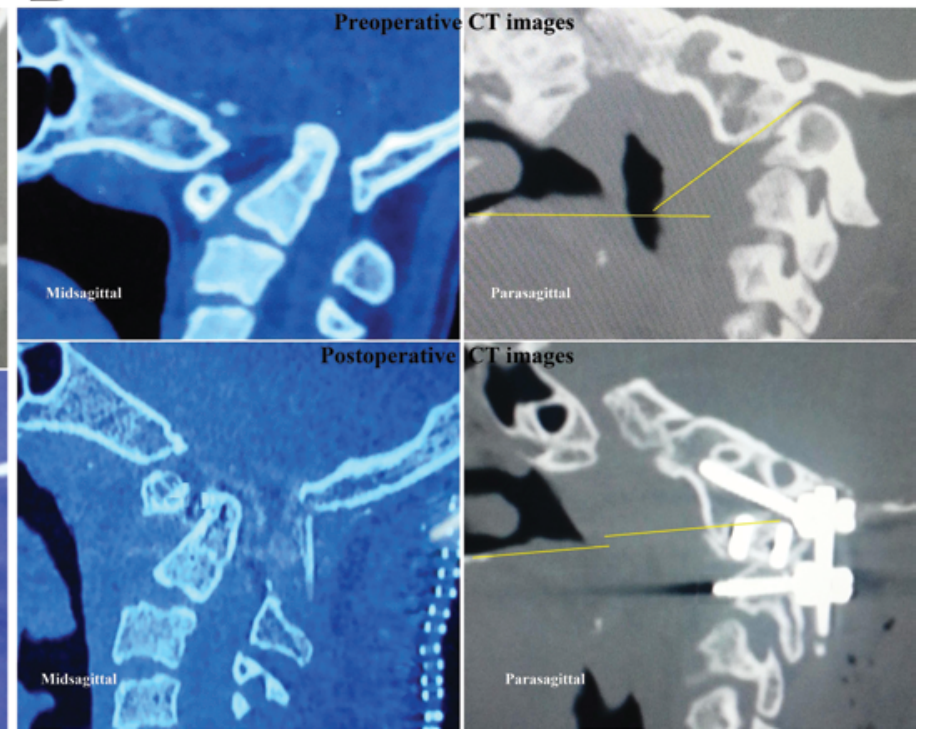

FIG. 4. Preoperative and postoperative CT scans of 2 patients ( $A$ and $B$ ) with congenital irreversible $A A D$ showing significant vertical and anteroposterior C1-2 dislocation. Note the obliquity of the facets in both patients (yellow lines showing acute C-1 inferior sagittal facet angle). The postoperative parasagittal images show the facets drilled to near normal or flat (yellow lines parallel to hard palate). Figure is available in color online only. 
tively less-acute facet angles. With more-acute angles, the degree of drilling increased significantly. We feared substantial instability with the use of sublaminar wires alone, following such extensive drilling. Therefore we switched over to lateral mass and pedicle screws.

Two patients developed graft (bone only) subsidence with partial vertical redislocation, with ADI progressing from $<3 \mathrm{~mm}$ in the immediate postoperative period to $5 \mathrm{~mm}$, which was observed on the CT scan obtained at 4 months. Both patients did not worsen clinically (with minimal dependence on others, JOA score 14) and did not undergo another operation. They continue to remain at the same clinical status. The CT scan at 9 months showed fusion in the same partially dislocated position. To avoid the complication of bone graft subsidence (due to possible resorption) leading to loss of height and redislocation, we switched to using metallic spacers in the last 1.5 years. We noted no dislodgements or redislocations since the use of metallic spacers. Fusion was observed in most patients 4-6 months after surgery and in all patients on CT performed 9-12 months postoperatively (Fig. 5).

\section{Discussion}

The atlantoaxial joints provide maximum mobility. This mobility, however, comes at the cost of stability. The neural structures and adjoining VAs make dislocation at this level dangerous. Atlantoaxial dislocations can be due to congenital bone anomalies, laxity of ligaments, or trauma. AADs are likely to reduce on extension. Currently the treatment of AAD is $\mathrm{C} 1-2$ arthrodesis in reduction. Certain AADs do not reduce on extension and even after application of traction. These types are referred to as irreducible AADs. It is important to know the cause of irreducibility so that the focus of treatment can be directed toward correcting it.

The C1-2 joints in congenital AADs are oblique (Fig. $1 \mathrm{~A}-\mathrm{C})$. Due to the obliquity in the sagittal plane, $\mathrm{C}-1$ tends to slip anteriorly and inferiorly over C-2.5 Also, the joints are vertical in the coronal planes, leading to vertical slipping of C-2 within C-1 (central or vertical dislocation). ${ }^{5}$ This obliquity can be measured objectively in the parasagittal and coronal planes as C-1 inferior sagittal and coronal facet angles. 5 The degree of joint obliquity determines the rate of slipping and the age at which the person is likely to present due to canal compromise. It appears that every congenital AAD is reducible to begin with and is a dynamic process. ${ }^{5}$ Additionally, C2-3 fusion and an oc- cipitalized atlas is often observed with congenital AAD. Such anomalies add to the stress at the $\mathrm{C} 1-2$ joints. Due to the acute angulation of facets, the reduction becomes difficult on extension and dislocation progresses until it becomes irreducible. ${ }^{5}$ At this point, the $\mathrm{C}-1$ facet has slipped significantly anteriorly and inferiorly relative to $\mathrm{C}-2$. The posterosuperior edge of the $\mathrm{C}-2$ facet itself acts like a ledge that prevents anteroposterior reduction on extension or even on minimal distraction provided by cervical traction (Fig. 1D-F). These abnormal movements should be labeled as translation and subsidence rather than dislocation. However, traditionally they have been referred to dislocation.

The focus in management of irreversible AAD has shifted from the compression (odontoid) to the cause of AAD. The pathology lies in the joints. Hence, the present treatment protocols have been directed toward reducing the joints by their intraoperative manipulation followed by fusion. ${ }^{1,2,5,6,8}$ Various techniques have been described to achieve intraoperative reduction. Goel's C1-2 joint distraction followed by placement of a spacer is a popular technique. ${ }^{1,2}$ Making the facet surfaces raw is important to aid fusion. The present technique emphasizes comprehensive drilling of the facets apart from making the surfaces raw. Drilling the posterior-superior wedge of C-2 and anterior inferior wedge of C-1 in congenital AAD makes the surfaces relatively flat and more like normal (Fig. 1G and $\mathrm{H})$. Drilling of the facets to nearly flat would convert an irreducible dislocation to a reducible one. Following this, the joints can be fused. Theoretically, such a facetectomy would avoid the tendency of C-1 slipping over C-2 until actual bone fusion occurs. The present technique also has an advantage of bone fusion due to extensive drilling.

There are certain disadvantages to this technique. The sectioning of the bilateral C-2 nerve root ganglion may cause occipital neuralgias, dysesthesias, or numbness. Interestingly, none of our patients complained of these in the postoperative period. Furthermore, sectioning of the C-2 root ganglion provides a panoramic view to the narrow corridor, and acts as a landmark for an anomalous VA; sectioning it under vision helps to mobilize the artery needed for safeguarding during joint manipulation. In addition, there is a theoretical possibility that stretching the C-2 nerve root ganglion during drilling and placement of spacers may injure the cord indirectly due to traction. The advantages of C-2 root ganglion sectioning appear to outweigh the disadvantages. The anomalous VA needs to be
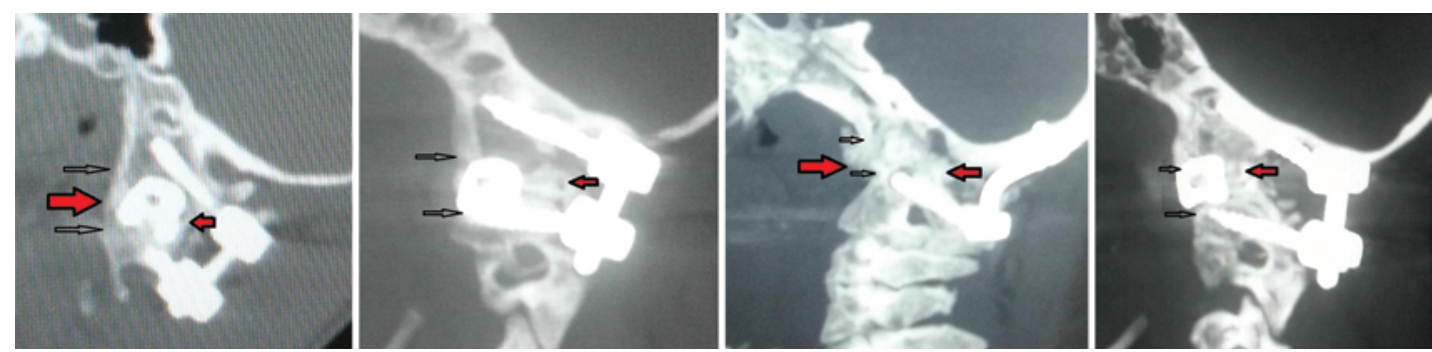

FIG. 5. Postoperative parasagittal CT scans of various patients showing good bone fusion of the $\mathrm{C} 1-2$ joint. Note the bony trabeculae between the C1-2 facets without any gap (red arrows). With metallic spacers, the trabeculae are observed anterior and posterior to the spacers, suggesting bone fusion. The drilled endplates (smaller, open arrows) and the periscrew region (area adjacent to the screws) show no lucencies, suggesting good fusion. Figure is available in color online only. 
dissected and safeguarded. ${ }^{3}$ A large exposure is required for such extensive drilling and the venous ooze can be bothersome at times. There is a potential danger of injuring the surrounding vital structures due to inadvertent slipping of the drill. Excessive drilling leads to loss of height, making placement of metallic spacers essential to avoid settling and reappearance of (central) vertical dislocation. The bone graft alone may not maintain the height until fusion due to graft subsidence (resorption), as was observed in 2 of our patients who underwent previous operations (see Table 1). Additionally, excessive drilling of C-2 may reduce the purchase for pedicle screws.

\section{Conclusions}

Comprehensive drilling of the $\mathrm{C} 1-2$ facets appears to be a logical and effective technique for achieving direct posterior reduction in irreversible AAD. The extensive drilling makes large surfaces raw, increasing the fusion rates.

\section{References}

1. Goel A: Treatment of basilar invagination by atlantoaxial joint distraction and direct lateral mass fixation. J Neurosurg Spine 1:281-286, 2004

2. Goel A, Kulkarni AG, Sharma P: Reduction of fixed atlantoaxial dislocation in 24 cases. Technical note. J Neurosurg Spine 2:505-509, 2005

3. Salunke P, Futane S, Sahoo SK, Ghuman MS, Khandelwal N: Operative nuances to safeguard anomalous vertebral artery without compromising the surgery for congenital atlantoaxial dislocation: untying a tough knot between vessel and bone. J Neurosurg Spine 20:5-10, 2014

4. Salunke P, Sahoo SK, Ghuman MS: Bilateral inverted vertebral arteries (V3 segment) in a case of congenital atlantoaxial dislocation: Distinct entity or a lateral variant of persistent first intersegmental artery? Surg Neurol Int 5:82, 2014

5. Salunke P, Sharma M, Sodhi HB, Mukherjee KK, Khandelwal NK: Congenital atlantoaxial dislocation: a dynamic process and role of facets in irreducibility. J Neurosurg Spine 15:678-685, 2011

6. Suh BG, Padua MR, Riew KD, Kim HJ, Chang BS, Lee CK, et al: A new technique for reduction of atlantoaxial subluxation using a simple tool during posterior segmental screw fixation. Clinical article. J Neurosurg Spine 19:160-166, 2013

7. Williams AL, Gornet MF, Burkus JK: CT evaluation of lumbar interbody fusion: current concepts. AJNR Am J Neuroradiol 26:2057-2066, 2005 Review

8. Yin YH, Qiao GY, Yu XG, Tong HY, Zhang YZ: Posterior realignment of irreducible atlantoaxial dislocation with $\mathrm{C1}$ C2 screw and rod system: a technique of direct reduction and fixation. Spine J 13:1864-1871, 2013

\section{Author Contributions}

Conception and design: Salunke. Acquisition of data: all authors. Analysis and interpretation of data: Salunke. Drafting the article: Salunke, Sahoo. Critically revising the article: Salunke.

\section{Correspondence}

Pravin Salunke, Department of Neurosurgery, PGIMER, Sector 12, Chandigarh 160012, India. email: drpravin_salunke@yahoo. co.uk. 